\title{
The Effect of the Cholesterol Levels on Noise-Induced Hearing Loss
}

\author{
Mehmet Gokhan Demir ${ }^{1}$ Sedat Aydin ${ }^{2}$ \\ 1 Department of ENT, Etimesgut State Hospital, Ankara, Turkey \\ 2 Department of ENT, Dr. Lutfi Kirdar Kartal Training and Researh State \\ Hospital, Istanbul, Turkey \\ Address for correspondence Mehmet Gokhan Demir, MD, \\ Department of ENT, Etimesgut State Hospital, Ankara 06800, Turkey \\ (e-mail: mgokhandemir@yahoo.com).
}

Int Arch Otorhinolaryngol 2018;22:19-22.

\begin{abstract}
Introduction Noise-induced hearing loss (NIHL), which is one of the most common occupational diseases among industrialized populations, is associated with longstanding exposure to high levels of noise. The pathogenesis of NIHL is not clear, but some genes and their activity at the tissue level have been investigated. Hypercholesterolemia, which can disturb the microcirculation, can be one of the underlying pathologies in hearing loss.

Objective To investigate the relationship between NIHL and hypercholesterolemia.

Methods The study group was selected among workers who had an occupational exposure of $85 \mathrm{~dB}$ of noise for at least 10 years. The audiologic assessment was recorded at seven frequencies $(500 \mathrm{~Hz}, 1,000 \mathrm{~Hz}, 2,000 \mathrm{~Hz}, 3,000 \mathrm{~Hz}, 4,000 \mathrm{~Hz}$, $6,000 \mathrm{~Hz}$ and $8,000 \mathrm{~Hz}$ ). A total of 456 workers were included in the study and divided into two groups: the control group (252 patients) and the NIHL group (204 patients). After the audiologic measurement, blood samples were taken and investigated for blood cholesterol levels. According to these results, the groups were compared.

Results Both groups were similarly distributed regarding age and occupational exposure time $(p>0.05)$. We could not detect any association between cholesterol levels and noise-induced hearing loss $(p<0.05)$. According to logistic regression analyses, the odds ratios are not significant for both hypercholesterolemia and hypertriglyceridemia $(p>0.05)$.

\section{Keywords}

- hypercholesterolemia

- occupational disease

- hyperlipidemia

- hearing loss

- noise-induced

Conclusion Noise-induced hearing loss is still a common occupational problem that can be prevented by hearing conservation programs and occupational health and safety training. Still, we know little about the relationship between NIHL and hypercholesterolemia. According to our findings, we cannot detect any relationship. Controlled studies and studies with human individuals can be made possible in the future with diagnostic innovations in tissue imaging and tissue microcircular sampling.
\end{abstract}

\section{Introduction}

Occupational diseases are quite prevalent in industrialized countries, and noise-induced hearing loss (NIHL) is a common disorder from this spectrum of diseases. Hearing loss may be associated with prolonged exposure to high-frequency noise, or with the poor health condition of the patient. $^{1,2}$ Although worker education may contribute to prevent this occupational disorder, gene dysfunctions and genetic disorders such as hyperlipidemia are not preventable. The demonstration of an association between hyperlipidemia and NIHL may allow physicians to take measures to prevent this occupational disease. Although a clear-cut association has not yet been shown, a previously received

September 28, 2016

accepted

March 23, 2017

published online

April 28, 2017
DOI https://doi.org/

10.1055/s-0037-1602774. ISSN 1809-9777.
Copyright $\odot 2018$ by Thieme Revinter

Publicações Ltda, Rio de Janeiro, Brazil
License terms

(c) (i) $\ominus$ (\$) 
published study has suggested that the microcirculation of the inner ear may be impaired in patients with hyperlipidemia. ${ }^{3}$ In this study, we aimed at assessing the potential associations between hyperlipidemia and NIHL.

\section{Material and Methods}

This cross-sectional study was conducted in our ear, nose and throat (ENT) clinic between December 2014 and December 2015. The workers to be included in the study were selected among those who had been exposed to at least $85 \mathrm{~dB}$ of occupational noise for at least 10 years. The workers who were included in the study were mainly from metallurgy, engine manufacturing and foundry industries. All participants were examined by an experienced physician. The exclusion criteria were previous ear surgery, sudden hearing loss, ototoxic drug use, history of ear trauma, any chronic disease, regular drug use, history of familial hypercholesterolemia, and age $>45$ years. All participants provided informed consent forms and were informed about the study and the study tests.

Audiometric testing was performed by an experienced audiometrist using a Maico MA 53 Audiometer device (Maico Diagnostics, Berlin, Germany). Seven test frequencies were recorded during the audiometric tests: $500 \mathrm{~Hz}, 1,000 \mathrm{~Hz}$, 2,000 Hz, 3,000 Hz, 4,000 Hz, 6,000 Hz and 8,000 Hz. We defined occupational hearing loss as a notch observed at $3 \mathrm{kHz}, 4 \mathrm{kHz}$ and $6 \mathrm{kHz}$ with recovery at $8 \mathrm{kHz}{ }^{4}$ The study population was divided into a control group $(\leq 25 \mathrm{~dB})$ and an NIHL group ( $>25 \mathrm{~dB}$ ), based on the level of the hearing loss.

The study population was further divided into hypercholesterolemia ( $>200$ ), normal cholesterol level $(<200)$, hypertriglyceridemia and normal triglyceride level, based on the US National Institute of Health Adult Treatment Panel III (ATP III) guidelines. ${ }^{5}$

Blood samples for biochemistry analyses were collected at 08.00 Am following 12 hours of fasting. Blood total cholesterol, triglycerides, low-density lipoprotein (LDL) and highdensity lipoprotein (HDL) levels were measured. Total cholesterol, total triglycerides, and LDL cholesterol levels were measured by an enzymatic method, while the level of the HDL cholesterol was measured by the immunoinhibition method, using an Olympus AU 2700 analyzer (Olympus life and material science GmbH, Dublin, Ireland). The level of LDL cholesterol was calculated by the Friedewald's formula, as follows:

$$
\mathrm{LDL}=\text { total cholesterol }-(\mathrm{HDL}+\text { total triglycerides } / 5) .
$$

The Statistical Package for the Social Sciences (SPSS) 22.0 software (IBM SPSS Statistics, Armonk, NY, USA) was used for the statistical analyses. The correlation analysis was used to detect correlations among the data. Descriptive data were presented as means \pm standard deviation (SD), and the Student's $t$-test was used for continuous data. The logistic regression analysis was used to estimate the odds ratios (at a $95 \%$ confidence level $[95 \% \mathrm{CI}]$ ). Any $p$-value lower than 0.05 was considered statistically significant.

This study was conducted in line with the 2013 version of the Declaration of Helsinki. The study was approved by the Institutional Review Board (decision No. 2014-89513307/ 1008/398).

\section{Results}

A total of 608 workers were screened, and 152 workers who did not met inclusion criteria were excluded from the study. The remaining 456 workers aged 30 to 45 years were included in the study. Based on the hearing level, 252 subjects were included in the control group, and 204 subjects were included in the NIHL group. Descriptive data by group are shown in - Table 1 . The groups were matched by age and occupational exposure $(p>0.05)$.

No association was found between the blood cholesterol level and the NIHL $(p>0.05)$. The analyses of the sub-groups did not reveal any significant difference. Based on the logistic regression analyses, the odds ratio for hypercholesterolemia was found to be 0.948 (95\%CI: $0.786-1.142 ; p>0.05$ ), and for hypertriglyceridemia, it was 0.928 (95\%CI: 0.886-1.162; $p>0.05$ ). In addition, no significant difference was found between the blood HDL level and the level of exposure to noise.

\section{Discussion}

Factors underlying sensorineural hearing loss have been previously investigated in many studies that followed several study models. Viral infections, tumors, ototoxic drugs, ear

Table 1 Comparison of the control group and the noise-induced hearing loss (NIHL) group

\begin{tabular}{|l|l|l|l|l|l|}
\hline \multirow{2}{*}{} & \multicolumn{2}{l}{ Control Group } & \multicolumn{2}{l|}{ NIHL group } & \multirow{2}{*}{$p$-value } \\
\cline { 2 - 6 } & Mean & SD & Mean & SD & \\
\hline Age (years) & 38.04 & 4.58 & 37.8 & 4.75 & 0.865 \\
\hline Occupational exposure to noise (years) & 13.24 & 2.04 & 13.0 & 2.24 & 0.713 \\
\hline Total cholesterol level (mg/dL) & 161.68 & 19.11 & 161.45 & 19.93 & 0.969 \\
\hline Triglyceride level (mg/dL) & 123.08 & 14.45 & 122.15 & 14.09 & 0.829 \\
\hline Low-density lipoprotein (mg/dl) & 115.6 & 10.74 & 115.8 & 10.84 & 0.951 \\
\hline High-density lipoprotein (mg/dL) & 44.64 & 8.05 & 43.95 & 8.19 & 0.778 \\
\hline
\end{tabular}

Abbreviations: NIHL, noise-induced hearing loss; SD, standard deviation. 
surgery, chronic middle ear infections, trauma and medical conditions were found to be associated with this pathological condition. Hypercholesterolemia is an important condition that may lead to sensorineural hearing loss, and may contribute to sensorineural hearing loss in a variety of ways. ${ }^{6}$ Noise-induced hearing loss may only result from prolonged exposure to noise. The pathogenesis and predisposing factors for this occupational condition remain unknown. Studies using animal models and histopathological analyses in humans have aimed at determining the underlying mechanism of hearing loss. These studies indicated cellular damage and functional loss in the organ of Corti, in a similar way to ototoxicity studies. Furthermore, there are studies indicating elevated reactive oxygen species (ROS) levels in the inner ear, following the exposure to noise. These oxidative products affect neurosensory epithelium (NSE) cells, such as inner hair cells (IHCs), outer hair cells (OHCs) and supporting cells. ${ }^{7-9}$

Another molecular mechanism under investigation is the genetic predisposition. Previous studies demonstrated that acoustic trauma might induce the activation of extracellular signal-regulated kinases (ERKs) and phosphorylation in the IHCs. Although this mechanism was demonstrated at the level of the neurosensory epithelial tissue, it is not clear whether these genes have protective or damaging effects, since there are controversial publications for both situations. ${ }^{7-11}$

All of these studies were based on the exposure to shortterm, high-frequency noise. ${ }^{12,13}$ Controlled human studies with histopathological analyses cannot be conducted due to ethical issues.

Another factor that may lead to hearing loss is the insufficient microcirculation in the inner ear. ${ }^{13}$ This problem may be associated with atherosclerosis and hypercholesterolemia. ${ }^{14}$ Microcirculatory disturbance in the inner ear may result in sudden hearing loss, since the inner ear has no collateral microcirculation. However, this situation may not be involved in the development of NIHL. Whether or not there is an association between vascular insufficiency and NIHL is a question that remains unanswered. Only the circulatory measurements and histopathological examination of the blood vessels may provide an answer to this question.

Cochlear microcirculation has been studied in in vivo animal studies integrated with mathematic models; however, we do not yet have any effective diagnostic screening tools. $^{15,16}$

In this study, we investigated the potential associations between the blood cholesterol levels of the workers and their hearing level. As stated in the Methodology section, comparisons were performed between cholesterol groups and the total duration of the exposure to noise. According to our results, no significant association was found between cholesterol levels and NIHL. Although the results of previous studies are in line with those of our study, the total duration of the exposure to noise and the different cholesterol levels were not analyzed in those studies. ${ }^{17}$ Unlike our study, certain studies found associations between an increased incidence of NIHL and hypertriglyceridemia as well as hy- percholesterolemia. All of those studies had limitations due to the potential bias resulting from the total duration of the exposure to noise and the wide age distribution. In addition, those studies lacked histopathological verification, as did ours. $^{18}$

It is a well-known fact that life expectancy has been increasing during the last century, and, therefore, the elimination of daily environmental noise sources as well as the elimination of presbyacusis present challenges. Consequently, postmortem histopathological studies have limited contribution when it comes to shedding light on this issue.

\section{Conclusion}

Noise-induced hearing loss is an ongoing occupational problem that may be prevented by hearing conservation programs and workplace health and safety trainings. Currently, we have limited knowledge on the potential associations between NIHL and hypercholesterolemia. Controlled human studies are limited, and a comprehensive study design is not feasible due to ethical issues. We will effectively assess this potential association in the future, provided that further advances in microcirculation imaging technologies are made, and that these technologies become available for clinical use.

\section{References}

1 Rabinowitz PM. Noise-induced hearing loss. Am Fam Physician 2000;61(09):2749-2756, 2759-2760

2 Fortunato G, Marciano E, Zarrilli F, et al. Paraoxonase and superoxide dismutase gene polymorphisms and noise-induced hearing loss. Clin Chem 2004;50(11):2012-2018

3 Hirano K, Ikeda K, Kawase T, et al. Prognosis of sudden deafness with special reference to risk factors of microvascular pathology. Auris Nasus Larynx 1999;26(02):111-115

4 McBride DI, Williams S. Audiometric notch as a sign of noise induced hearing loss. Occup Environ Med 2001;58(01):46-51

5 Adult treatment panel III of national cholesterol education program NIH publication 2001;1(5):3305

6 Evans MB, Tonini R, Shope CD, et al. Dyslipidemia and auditory function. Otol Neurotol 2006;27(05):609-614

7 Roberson DW, Rubel EW. Cell division in the gerbil cochlea after acoustic trauma. Am J Otol 1994;15(01):28-34

8 Hudspeth AJ. How hearing happens. Neuron 1997;19(05): 947-950

9 Fukui H, Wong HT, Beyer LA, et al. BDNF gene therapy induces auditory nerve survival and fiber sprouting in deaf Pou $4 \mathrm{f} 3$ mutant mice. Sci Rep 2012;2:838

10 Kurioka T, Matsunobu T, Satoh Y, et al. ERK2 mediates inner hair cell survival and decreases susceptibility to noise-induced hearing loss. Sci Rep 2015;5:16839

11 Lahne M, Gale JE. Damage-induced activation of ERK1/2 in cochlear supporting cells is a hair cell death-promoting signal that depends on extracellular ATP and calcium. J Neurosci 2008; 28(19):4918-4928

12 Xia Z, Dickens M, Raingeaud J, Davis RJ, Greenberg ME. Opposing effects of ERK and JNK-p38 MAP kinases on apoptosis. Science 1995;270(5240):1326-1331

13 Battaglia A, Pak K, Brors D, Bodmer D, Frangos JA, Ryan AF. Involvement of ras activation in toxic hair cell damage of the mammalian cochlea. Neuroscience 2003;122(04):1025-1035 
14 Arthur DB, Georgi S, Akassoglou K, Insel PA. Inhibition of apoptosis by P2Y2 receptor activation: novel pathways for neuronal survival. J Neurosci 2006;26(14):3798-3804

15 Harding GW, Bohne BA, Vos JD. The effect of an age-related hearing loss gene (Ahl) on noise-induced hearing loss and cochlear damage from low-frequency noise. Hear Res 2005; 204(1-2):90-100
16 Henderson D, Bielefeld EC, Harris KC, Hu BH. The role of oxidative stress in noise-induced hearing loss. Ear Hear 2006;27(01):1-19

17 Suzuki K, Kaneko M, Murai K. Influence of serum lipids on auditory function. Laryngoscope 2000;110(10 Pt 1):1736-1738

18 Choudhury N, Chen F, Shi X, Nuttall AL, Wang RK. Volumetric Imaging of Blood Flow within Cochlea in Gerbil in vivo. IEEE J Sel Top Quantum Electron 2009;PP(99):1-6 